\title{
Towards an enriched framework of service evaluation for pedestrian and bicyclist infrastructure: acknowledging the power of users' perceptions
}

\author{
Alvaro Rodriguez-Valencia' (D) . Jose Agustin Vallejo-Borda ${ }^{2,3}$ (D) . \\ German A. Barrero ${ }^{4}\left[\right.$. Hernan Alberto Ortiz-Ramirez ${ }^{4}(\mathbb{C}$
}

Accepted: 20 April 2021 / Published online: 9 May 2021

(c) The Author(s) 2021

\begin{abstract}
More and more cities worldwide are striving for sustainability and livability. Measuring the service or performance of local-scale spaces for pedestrians and bicyclists to better understand how to provide "walkable" and "bikeable" environments is key in this endeavor to enhance active transportation. These pedestrian and bicycle service or performance indicators, such as Level of Traffic Stress or Level of Service, relate measurable characteristics with a perceived proxy of the performance or service, such as comfort, satisfaction, or quality of service (QoS). The purpose of this study is to propose and validate a framework that integrates user-oriented inputs to the existing traditional supply-oriented variables to explain the QoS in segment roadways in urban environments for active modes. The conceptual framework underlying this study considers the contribution of individual perceptions, in addition to the traditionally considered operational and geometry variables, to explain the perceived QoS of pedestrian and bicyclist infrastructure. The framework is tested via two separate and independent surveys for pedestrians and bicyclists. Evidence determined the relative importance of these supply-oriented and user-oriented factors to explain the QoS. The superior explanatory power of the perception variables and in terms of the variables that explain the individuals' perceived QoS justify the framework for both pedestrians and bicyclists.
\end{abstract}

Keywords Perceptions · Pedestrians · Bicyclists · Experience $\cdot$ User centered $\cdot$ Active transportation

\section{Introduction}

More and more cities worldwide are striving for sustainability and livability. Active transportation is key to this endeavor. Enhancing "walkable" and "bikeable" cities has been proved as beneficial to physical and mental health, to the reduction of pollution, mitigation

Alvaro Rodriguez-Valencia

alvrodri@uniandes.edu.co

Extended author information available on the last page of the article 
of global warming, in terms of resources, safety, and many other personal and societal dimensions (Garrard et al. 2008; Maizlish et al. 2017; Pucher and Buehler 2017; World Health Organization 2002; Xia et al. 2017). As such, disciplines related to transportation engineering, urban design, street design, environmental engineering, and public health have joined in the common goal to provide a comprehensive understanding of the drivers behind encouraging more people to change modes of transportation to active modes.

Many tools for measuring the service or the performance of spaces at local scale for pedestrians and bicyclists have been developed during the past decades. These include the Level of Service-LOS (for pedestrians and bicyclists) (Roess et al. 2010), the WalkScore (for pedestrians) (Duncan et al. 2011), the Level of Traffic Stress (for bicyclists) (Furth et al. 2016; Mekuria et al. 2012; Wang et al. 2016), and the Environmental Quality Index (for pedestrians and bicyclists) (Health and Team 2010), among others. These pedestrian and bicycle Service or Performance Indicators (hereafter referred to as SPI) relate objective and measurable right-of-way characteristics, conditions, and attributes with a perceived proxy of the performance or service, such as comfort, satisfaction, and quality of service.

The explanatory variables for the SPIs are, in the vast majority of cases, supply oriented. For pedestrian and bicyclist Level of Service (hereafter referred to as LOS), Roess et al. (2010) summarize the attempts made via the Highway Capacity Manual to incorporate active modes in the methodology by classifying the explanatory variables in two big groups: geometry variables (G-variables), such as infrastructure width; and operational variables (O-variables), such as the traffic volumes or traffic composition. Table 1 summarizes a list of explanatory variables found in the literature, including other methods and studies besides the LOS.

Table 1 List of variables used in the literature to explain SPIs. Obtained from: Asadi-Shekari et al. (2013), Dandan et al. (2007), Gallin (2001), Harkey (1998), Jensen (2007), Landis et al. (1997, 2001a), Pikora et al. (2003), Roess et al. (2010) and Transportation Research Board (2010)

\begin{tabular}{lll}
\hline Variable & Pedestrians & Bicyclists \\
\hline Geometric & Sidewalk width & Bike lane width \\
& Number of vehicular lanes & Number of vehicular lanes \\
& Bicycle infrastructure presence & Distance from pedestrians \\
& Buffer width & Separation from traffic \\
& Driveways segment length & Driveway density \\
& Sidewalk presence & Presence and type of sidewalk \\
& Accessibility details (e.g., ramps) & Intersection details \\
& Road width & Road width \\
Operational & Speed of motorized vehicles & Speed of motorized vehicles \\
& The proportion of HGV in the motorized & The proportion of HGV in the motorized \\
& traffic & traffic \\
& The flow of directional traffic of bicycles & The volume of directional traffic of bicycles \\
& On-street parking & Parked vehicles \\
Conflicts & Hindrances \\
& Pedestrian flow & Cyclists volume \\
\hline
\end{tabular}


Recent literature suggests that beyond these groups of variables, there are other built environment characteristics to be considered (Nag et al. 2019). For example, the surface condition has been found to be a relevant aspect for both pedestrians and bicyclists (Asadi-Shekari et al. 2013; Gallin 2001; Samarasekara et al. 2011). Other relevant variables that are not necessarily geometric or operational and have been identified as significant are on-street signage, land uses, weather, and type of buffer (Asadi-Shekari et al. 2013; Foster et al. 2016; Gallin 2001; Jensen et al. 2007; Kadali and Vedagiri 2015; Landis et al. 1997; Pikora et al. 2003).

However, the literature on the assessment of the performance and service of pedestrian and bicyclist infrastructure has not often considered user input to explain SPI levels and its implications in driving changes in choice behavior. Pedestrians and bicyclists, unlike motorists, consciously and unconsciously interact with their surroundings, while moving in the street (Barrero and Rodriguez-Valencia 2021; Ma and Cao 2019). Perception is the mean that makes it possible to connect the stimuli from the built environment to individuals' emotional responses (Ali et al. 2020; Ma and Cao 2019; Mehrabian and Russell 1974; Ortiz-Ramirez et al. 2021; Yani-de-Soriano and Foxall 2006). According to Ewing et al. (2006), pedestrian perceptions of the street environment may have complex relationships with physical features, and these physical features may not reveal much about user opinions of a specific location. In the case of transportation, perceptions of both intangible features (e.g., safety perception), and physical attributes (e.g., pavement perception) can explain the pedestrian quality of service (Vallejo-Borda et al. 2020a, b) or cyclits service assessment (Barrero and Rodriguez-Valencia 2021; Vallejo-Borda et al. 2019, 2020c). Satisfied and content users generate attachment to the service, recommendations to other potential users, and repetition (Tyler et al. 1999).

The purpose of this paper is to propose a framework explaining the pedestrian and bicyclist quality of service (QoS) at roadway segments that enhances associations with the activities and behaviors pertaining to these modes. Specifically, the aim here is to understand the underlying process that leads pedestrians and bicyclists to evaluate the quality of service for urban street segments, differentiating it from traditional LOS methodologies for motorized traffic. We also explore the statistically significant perceptual variables that explain the perceived QoS of the infrastructure of active mobility users.

\section{Proposed conceptual framework}

The conceptual framework underlying this study considers the contribution of individual perceptions, in addition to the traditionally considered operational and geometry variables, to explain pedestrian and bicyclists' QoS, and its association with walking and biking behavior (see Fig. 1). Adding perceptions as variables able to explain SPIs broadens the perspective of pedestrian and bicyclist service and performance evaluation, which affects both walking and biking behavior (i.e., active traveling). The framework provides concise, understandable relations, that summarize previous research and new findings, for practical application. As recommended by van Acker et al. (2010) the framework is based on mixed findings from the travel behavior and psychology fields.

\section{Service and performance indicators (SPI): evolution and application}

The first SPI for pedestrians and bicyclists was the Level of Service (PB-LOS). Since pedestrian and bicycle traffic presents the same general flow conditions as the motorized traffic (i.e., declining speed at higher densities), early PB-LOS methods related good 


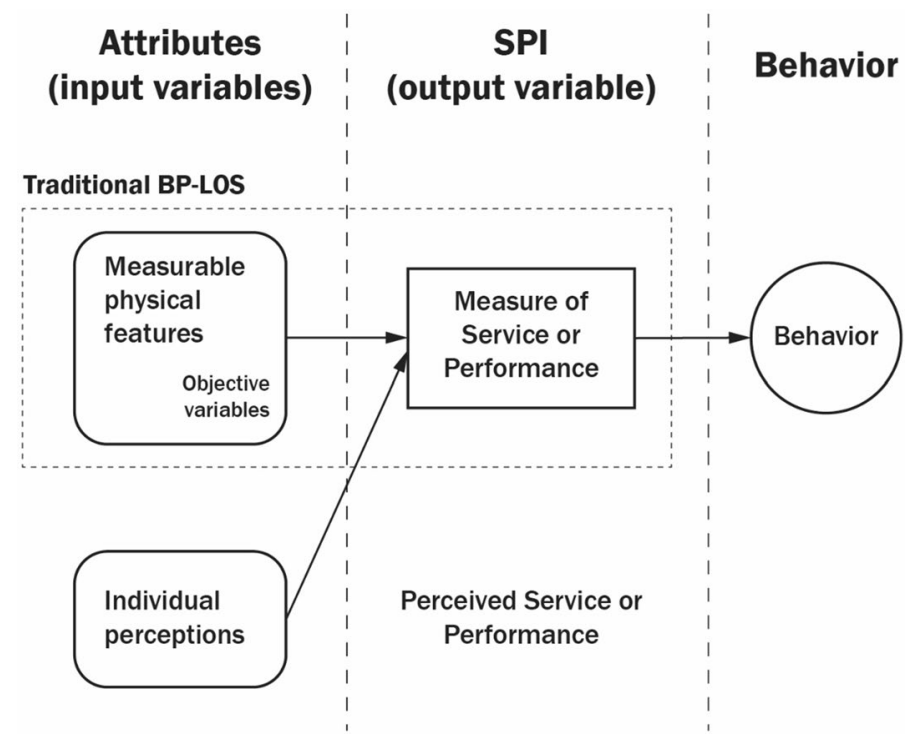

Fig. 1 Conceptual framework

service with less congestion. Accordingly, similarly to highway principles, for a given demand, providing extra capacity (wider sidewalks or bike-paths) means better LOS, as the early PB-LOS methods indicated in the 1980s. The late 1990s and early 2000s witnessed the development of more advanced models to evaluate local scale SPIs. Landis et al. (1997, 2001b, 2003), and Petritsch et al. (2005) found that other factors beyond the volume-capacity relationship could affect pedestrian and bicycle-LOS, respectively. Besides the width of the dedicated infrastructure, many other geometry related variables (G-variables), such as separation of the motorized traffic, were included in the equation. Also, motorized traffic variables, such as speed, composition, or volumes, were found to be significant in explaining PB-LOS (called operational variables or O-variables). The state-of-the-practice for LOS for urban streets considers that the infrastructure is evaluated from the perspective of the service it provides to the different users, establishing a multimodal LOS approach introduced in 2010 (Transportation Research Board 2010).

In the last two decades, new SPIs were developed to explain the selected perceived service or performance indicator (service, stress, comfort, etc.), which consider O-variables and G-variables as explanatory in multi-variable models. Some of the most popular SPIs include the Level of Traffic Stress (LTS) for bicycles, and different applications of the Walkability Index for pedestrians (Appolloni et al. 2019; Ewing and Handy 2009; Guo and Loo 2013; Koohsari et al. 2016; Lee and Talen 2014; Marquet and Miralles-Guasch 2015; Peiravian et al. 2014; Sehatzadeh et al. 2011; Shatu and Yigitcanlar 2018; Stockton et al. 2016; Tsiompras and Photis 2017). The Level of Traffic Stress is based on the classification of road segments into four different levels of stress related to bicyclists' riding abilities (Huertas et al. 2020). Each segment or intersection is classified according to its operational (e.g., speed limit, prevailing speed, on-lane interferences or blockages, intersection interferences) and geometric characteristics (e.g., street width, bike lane width, separation, number of lanes per direction, intersection geometry, connectivity) (Furth et al. 2016; Mekuria et al. 2012). Likewise, Walkability indices have been developed to estimate how 
pedestrian-friendly an infrastructure can be. These indices also commonly include O-variables [e.g., intersection density (Peiravian et al. 2014; Shatu and Yigitcanlar 2018), connectivity (Tsiompras and Photis 2017), local road density, and safety (Sehatzadeh et al. 2011)], as well as G-variables [e.g., sidewalk width, building height (Shatu and Yigitcanlar 2018), and proportion of street walls and first floor with windows (Ewing and Handy 2009)].

Despite the robust set of literature concerning SPIs for pedestrians and bicyclists, it is not common to find perceptual variables that account for explanators in these indices. In the vast majority of cases, these objectively measured features of the streetscape environment have been considered to understand, evaluate, and design any bicycle or pedestrian facilities. It is only very recently, that research on pedestrian SPIs has included user perceptions and behavioral and attitudinal factors (Griswold et al. 2018). Only recently, in the literature, perceptions have been considered, mainly to identify latent variables and to evaluate the impacts of these latent variables on the perceived QoS (Jahan et al. 2020; Vallejo-Borda et al. 2020a) or LOS (Bivina and Parida 2019). The state-of-the-art of QoS forecasting methodologies by means of objectively measured attributes for pedestrians, uses perceptions as mediators (Vallejo-Borda et al. 2020b).

\section{Behavioral theories and the pedestrian and bicyclist SPI relevance}

Within the past decade, a considerable amount of research has been carried out, at varying degrees of depth and sophistication, on the drivers that make people change their behavior as part of a sustainable transportation perspective. Literature has shown that choosing bicycling or walking as modes of transportation goes beyond the traditional mode choice theory, where travel time and costs are the main determinants, under the principles of utility maximization of rational travelers (De Vos et al. 2016; Fernández-Heredia et al. 2016; Griswold et al. 2018; Larrañaga et al. 2016; Ma and Cao 2019; Schneider 2013; van Acker et al. 2010). For example, Gatersleben and Uzzell (2007) showed that the enjoyment of non-motorized traveling itself could be a factor that positively influences the choice of such modes and overall satisfaction with the trip. Several frameworks and theories have been developed, where alternative approaches have unveiled interrelated factors and rationales in the mode selection of bicyclists and pedestrians.

Individuals' perceptions were found to be relevant in explaining affective and behavioral responses such as walking and bicycling in some of these studies. The study by Bornioli et al. (2019), for example, included the analysis of factors such as environmental perceptions, including aesthetics and interestingness. These factors were used to explain an individual's response to environmental stimuli and a further selection of walking as a traveling mode. To provide another example, the study by Fernández-Heredia et al. (2016) focuses on bicycle choice intention. It quantitatively introduces perceptions in a sequential modeling approach, of which the results proved that mode choice could be better explained by including psycho-social factors in the modeling processes.

Also, some travel behavior frameworks schematically showed the factors explaining active modes choice. In these frameworks, the role of perceptions has been theorized as being explanatory of mode choice and modal shifts towards sustainable modes (Schneider 2013), walking and bicycling (Pikora et al. 2003), walking and bicycling for recreation or exercise (Saelens et al. 2003), and walking (Ewing and Handy 2009). These frameworks have been proposed using qualitative evidence acquired from both users (Schneider 2013) and experts or literature (Ewing and Handy 2009; Pikora et al. 2003; Saelens et al. 2003; 
Schneider 2013). Besides, none of these studies have included a quantitative input directly acquired from user perceptions or any kind of index to measure the performance of infrastructure in relation to such perceptions.

\section{Other behavior theories from psychology and travel behavior}

Previous revised travel behavior frameworks propose that individuals' perceptions of contextual characteristics can influence behavioral intentions and responses. However, in the literature, there is weak empirical evidence of this relationship. Multiple studies generally propose that behavior can be influenced by affective or emotional responses to the stimuli perceived by a person in a particular space (Blaison and Hess 2016; Evans and Stecker 2004; Friman 2010; Gatersleben and Uzzell 2007; Jang and Namkung 2009; Ma and Cao 2019; Samuel et al. 2019; Yani-de-Soriano and Foxall 2006; Zhang et al. 2019). These stimuli come from different sources in the person's environment and are particularly important for travelers affected directly by the space in which they move (Samuel et al. 2019). Hence, understanding theories that relate cognitive and affective responses to the perception of such stimuli and behavioral responses could increase the knowledge on the relationship between a non-motorized SPI and behavior.

Behaviors are influenced by individuals' perceptions of the built environment, and some theories from travel behavior and social and environmental psychology have been proposed to explain how this process develops. In general terms, the stimulus-organism-response (SOR) framework, presented by Ma and Cao (2019), shows a mechanism that explains how environment characteristics affect individual states and behaviors. Mehrabian and Russell (1974) proposed a SOR related theory in which the authors suggest that three affective dimensions (i.e., pleasure, arousal, and dominance) can explain all the emotional states that an individual's perception of environmental stimuli can elicit. These dimensions indicate a primary emotional response that ultimately influences avoid or approach behaviors towards a place or situation (Ortiz-Ramirez et al. 2021), which is the most basic factor involved when contemplating walking or bicycling.

Perceptions are part of the formalization of individuals' attitudes. Stimuli influence perceptions and they, in turn, influence attitudes toward the stimulus (van Acker et al. 2010). Attitudes are presented by van Wee et al. (2019) as the degree of valuation an individual assign to something (e.g., an object or behavior). Hence, in the travel behavior field, attitudes acquire particular relevance because the valuation of modes or infrastructure, for example, can exert an influence on mode choice (Ma and Cao 2019). Behavioral responses, therefore, rely on individuals' perceptions of their environment and on their attitudes towards travel-related factors.

From this perspective, non-motorized SPIs can help to explain behaviors such as walking and bicycling. When including individuals' perceptions in non-motorized SPI estimations, these indicators can begin to account for users' affective responses towards contextual factors while traveling. Furthermore, such perceptions can contribute to the formalization of user attitudes towards a specific mode and hence, influence users' propensity to choose walking or bicycling as a mode of transportation. In other words, nonmotorized SPIs can provide information on crucial perceived variables that can influence the choice of non-motorized modes as a means to travel. 


\section{Methods}

To explore and evaluate user perspectives of non-motorized infrastructure Quality of Service (QoS), we analyzed data from two independent studies conducted for bicyclists (April and May 2017) and for pedestrians (June 2018) (see Table 2). The locations were carefully selected to attain a diverse sample between the non-motorized populations and to cover all typologies of different sidewalks (i.e., no lateral separation, lateral separation with no vertical barriers, lateral separation with vertical barriers, and on-street parking) and bicycle-dedicated infrastructures (i.e., segregated bike lane, a bike lane on the sidewalk, and bike lane on the road median) available in Bogota, Colombia. The locations audited for the study involving bicyclists are different from those audited for the pedestrian study.

The sample for pedestrians and bicyclists were distributed by age and sex like in the same ratio as Bogota's population using these modes (see the descriptive statistics in Table 3). Each survey (pedestrian and bicyclist) lasted approximately $8 \mathrm{~min}$, and the overall response rate for pedestrians was $33.2 \%$, and $27.5 \%$ for bicyclists. To attain randomness, data collection for both pedestrian and bicyclist surveys was developed by selecting respondents on a one in every three passing pedestrians/bicyclists basis. We carefully balanced users in both directions and we were strict in avoiding self-selection.

The fieldwork comprised the random interception surveys administered in-person to users. In-person survey administration is used to reduce biases of recalling emotions after the experience (Paül i Agustí et al. 2019; Yani-de-Soriano and Foxall 2006), traffic counts, and geometrical features and infrastructure audits. The questionnaire used in this study for pedestrians was based on the one developed for bicyclists, and has been

Table 2 Pedestrian and bicyclist survey information

Table 3 Sample composition

\begin{tabular}{lll}
\hline & Pedestrians & Bicyclists \\
\hline Sample size & 1056 & 432 \\
Number of locations & 30 & 16 \\
Starting date & June 2, 2018 & April 25, 2017 \\
End of campaign & June 19, 2018 & May 18, 2017 \\
Survey period & $08: 00$ to 18:00 & $7: 00$ to 9:00 \\
& & $11: 00$ to 13:00 \\
& & 8 min \\
\hline Duration of the survey & 8 min & \\
\hline
\end{tabular}

\begin{tabular}{lll}
\hline & Pedestrians (\%) & Bicyclists (\%) \\
\hline Sex & & \\
Male & 51.1 & 78.1 \\
Female & 48.9 & 21.9 \\
Age & & \\
$\leq 25$ & 35.8 & 24.4 \\
$26-40$ & 32.1 & 49.5 \\
$41-59$ & 21.8 & 23.6 \\
$\geq 60$ & 10.3 & 2.5 \\
\hline
\end{tabular}


used in other studies (Bellizzi et al. 2019; Rodriguez-Valencia et al. 2020; Rossetti and Hurtubia 2020). The questionnaire for bicyclists was based on Ferro Navas (2017) and the gathered data has been used in other studies (Vallejo-Borda et al. 2020c; Barrero and Rodriguez-Valencia 2021). Table 4 summarizes the basic information contained in the surveys.

The process followed in this study included: (1) identifying different pedestrian and bicyclist serviceability and performance indexes and indicators in the literature; (2) gathering existing data from the previous studies for both users, and planning and performing data acquisition for rights-of-way where incomplete audits where found (i.e., bicyclist study); (3) developing comparison and analysis methods through linear regression models estimation; (4) identifying the relevant perception variables that explain QoS for both users (pedestrians and bicyclists) through a stepwise regression analysis; and (5) discussing results.

Both user studies were conducted at Universidad de los Andes and the bicyclist survey was conducted over a year before the pedestrians one and pedestrians survey followed the same questionnaire structure and data acquisition process but included more questions and measured attributes. Besides this, the Likert scale for the pedestrian survey was modified and the categories were increased (i.e., from 1-5 to 0-10) based on modeling requirements related to complementary studies (i.e., Vallejo-Borda et al. $2020 \mathrm{a}, \mathrm{b}$ ) and to enhance the normality approximation (Wu and Leung 2017). Both survey questionnaires begin with a question about the overall perceived QoS in the specific location, sidewalk, or bike path (i.e., dependent variable). Following this, respondents were asked to rate a set of questions and statements about the attributes of the location and perceptions of intangible states, conditions, or emotions on a Likert-based scale. Finally, several socio-demographic questions were included in both questionnaires. The list of variables in the questionnaires is shown in Table 4.

We estimated seven OLS models (Eq. 1) combining different groups of variables, namely geometric (G-variables), operational (O-variables), and perceptional (P-variables) as presented in Table 5, separately for pedestrians and bicyclists. The independent variables in each group (i.e., G, O, and P) were selected as shown in Table 4. Only variables maximizing the coefficient of determination (R-squared) were kept for each group of variables. To uncover the contribution of each group of variables, the partial coefficient of determination (partial R-squared) was used as an indicator for each group of variables to explain the perceived QoS. The R-squared on a linear model is defined as the ratio between the explained variation and the total variation (Ortúzar and Willumsen 2011) and accounts for the percentage of variation of the dependent variable explained by the independent variables.

In this case, the partial R-squared is used to estimate the contribution of each group of variables to explaining the perceived QoS variance through commonality analysis. Kitamura et al. (1997) used a similar approach (to the one we used in this paper) to compute the incremental change in different groups of variables R-squared, based on the order of inclusion of these groups to the model. Besides, Scherrer et al. (2009) explained the partial R-squared calculation developed in this paper. Two indicators were chosen to compare the seven models: The F-test that is used to evaluate the goodness of fit of each model and the adjusted R-squared that is used to compare the overall proportion of variance explained by all the independent variables on each model. Adjusted R-squared is preferred over R-squared due to its capability to correct the impact of the number of independent variables, which makes it possible to compare the models (Washington et al. 2011). 


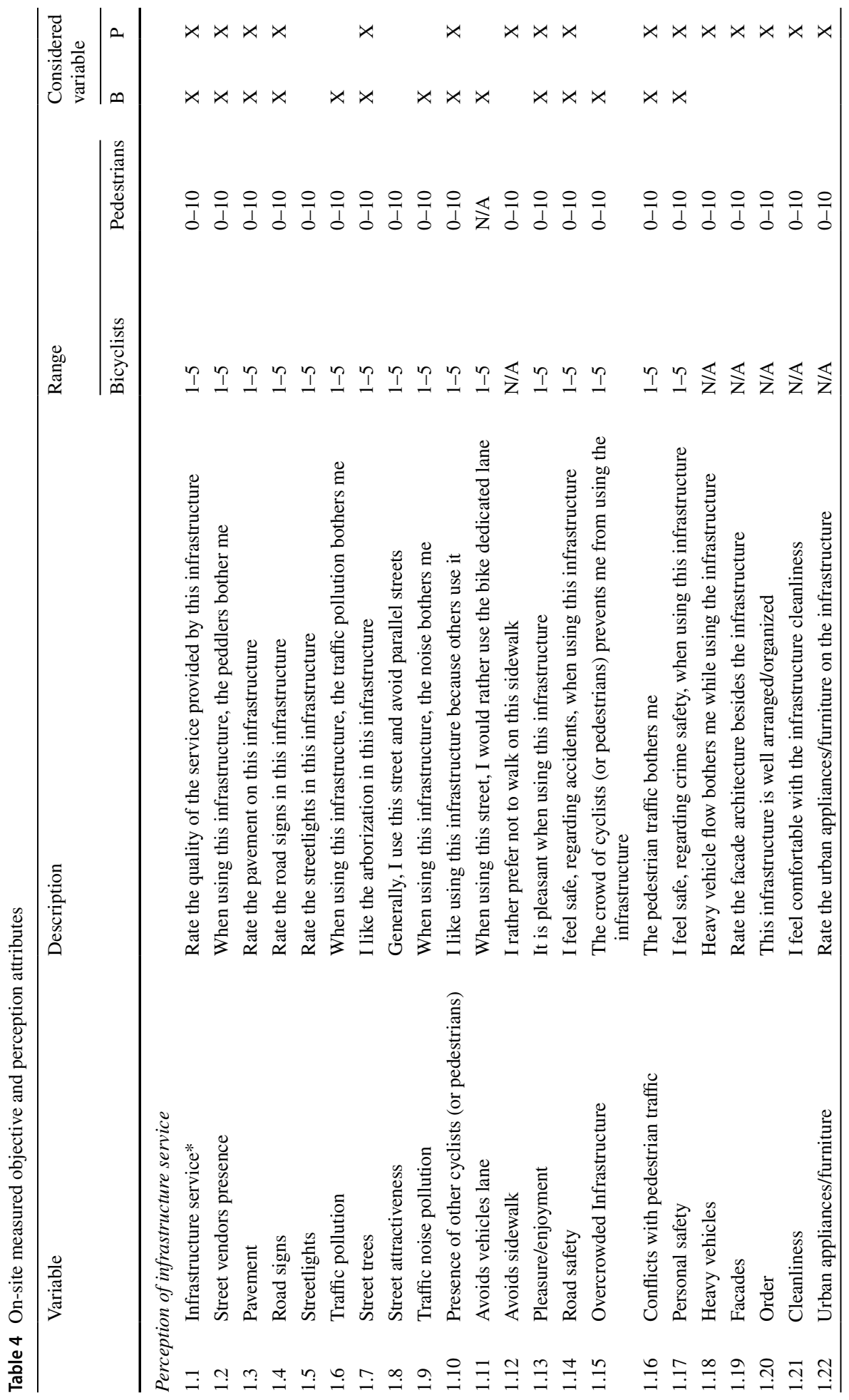




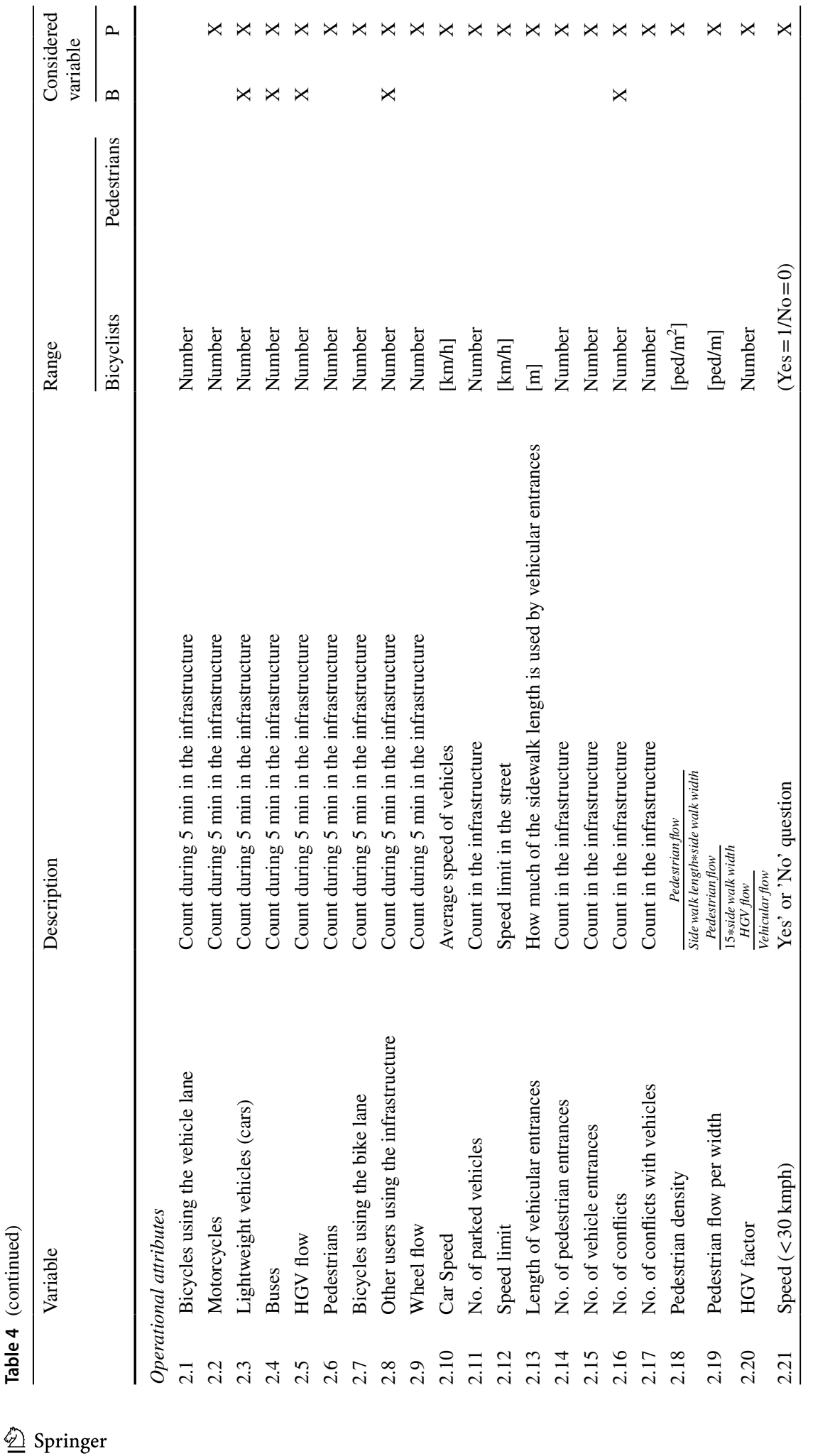




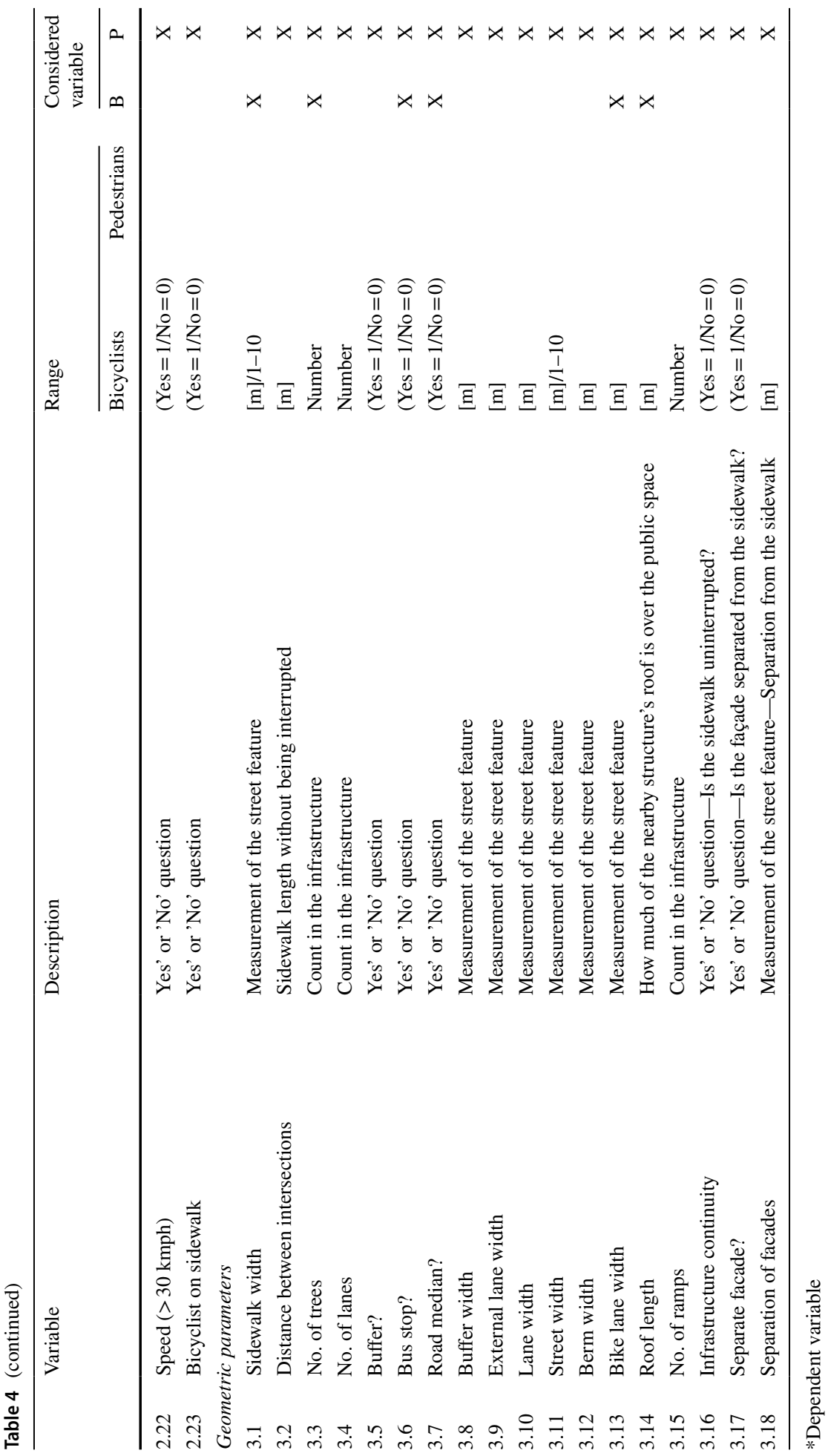


Table 5 Models generated to explain the perceived QoS

\begin{tabular}{llllllll}
\hline & Model 1 & Model 2 & Model 3 & Model 4 & Model 5 & Model 6 & Model 7 \\
\hline Geometric (G) factors & $\mathrm{X}$ & & & & $\mathrm{X}$ & $\mathrm{X}$ & $\mathrm{X}$ \\
Operational (O) factors & & $\mathrm{X}$ & & $\mathrm{X}$ & $\mathrm{X}$ & & $\mathrm{X}$ \\
Perceptional (P) factors & & & $\mathrm{X}$ & $\mathrm{X}$ & & $\mathrm{X}$ & $\mathrm{X}$ \\
\hline
\end{tabular}

$$
Y_{i}=\beta_{0}+\sum_{1}^{g} \sum_{1}^{k_{g}} \beta_{k_{g}} x_{i, k_{g}}+\varepsilon
$$

where $Y$, dependent variable (i.e., 1.1 infrastructure service); $\beta_{0}$, intercept; $g$, group of variables; $k_{g}$, Number of variables in each group $g ; \beta$, vector of estimable parameters $x ; x$, vector of independent variables; $\varepsilon$, error term; $i$, number of observations.

In a subsequent step, to develop parsimonious models with a subset of significant perceptual variables (at 90\% significance level), we performed a stepwise regression procedure. This kind of model relies on the comparison of competing OLS models and the selection of the best of them based on a chosen goodness of fit criterion (Washington et al. 2011). In this case, the chosen criterion is the AIC (Akaike's information criterion), which considers the model's goodness of fit and the number of estimated parameters (Golob 2003; Washington et al. 2011) the lower the AIC, the better the model. The competing models are generated using both forward (i.e., adding an independent variable in each step) and backward (i.e., eliminating an independent variable in each step) methodologies in an iterative process that minimizes the AIC until the best regression model is achieved. To identify which specific P-variables seem to be significant in explaining the perceived QoS for both modes, we estimated stepwise regressions, including only this set of variables.

Since our study focuses on understanding the impact of individuals' perceptions on SPIs in the proposal of a new framework, we used models that explain the perceived QoS of each individual, rather than the average sidewalk QoS evaluation. Evaluating average QoS for each location would have reduced the degrees of freedom as long as the dependent variable and the G-variables would not varied for each for the several individuals interviewed in each location, and hence the effects of the individual users' heterogeneity would have been neglected. With this approach and considering the diversity established in the experiment design, we also tried to reduce multicollinearity problems (Gujarati and Porter 2010). By analyzing QoS variance at an inter-individual scale, we can identify the effects of independent variables on each individual reported QoS. On the other hand, if the mean of the total observations were estimated for each location, individual measures would have been lost. Also, the number of observations would have decreased, and the models would not be estimable under such restrictions.

\section{Supporting evidence}

The similarities between pedestrians and bicyclists attract attention, despite the independence in the source of data and models. The separated and combined contribution of O-variables, G-variables, and P-variables to explain individual perceived QoS (Table 6) show an overwhelming dominance of P-variables, for both transportation modes. Besides, the similarity in the contribution of different groups of variables, either in the quantity of variance explained and proportion among groups of variables, reveals something beyond chance. The independent variables used for each model are shown on Table 4. The pure 
Table 6 Disaggregated contribution of the three groups of variables to the overall coefficient of determination for pedestrians and bicyclists

\begin{tabular}{|c|c|c|c|c|c|c|c|c|c|}
\hline Model & & $x^{*}$ & $\mathrm{G}$ (pure) & $\mathrm{O}$ (pure) & $\mathrm{P}$ (pure) & Comm.** & R-sq & Adj-R-sq & F-stat \\
\hline \multirow[t]{2}{*}{ M1 } & PED & 18 & $\begin{array}{l}0.164 \\
(100.0 \%)\end{array}$ & & & n.a & $\begin{array}{l}0.164 \\
(100.0 \%)\end{array}$ & 0.150 & 11.310 \\
\hline & BIKE & 6 & $\begin{array}{l}0.108 \\
(100.0 \%)\end{array}$ & & & n.a & $\begin{array}{l}0.108 \\
(100.0 \%)\end{array}$ & 0.093 & 7.486 \\
\hline \multirow[t]{2}{*}{ M2 } & PED & 23 & & $\begin{array}{l}0.153 \\
(100.0 \%)\end{array}$ & & n.a & $\begin{array}{l}0.153 \\
(100.0 \%)\end{array}$ & 0.134 & 8.102 \\
\hline & BIKE & 5 & & $\begin{array}{l}0.121 \\
(100.0 \%)\end{array}$ & & n.a & $\begin{array}{l}0.121 \\
(100.0 \%)\end{array}$ & 0.109 & 10.290 \\
\hline \multirow[t]{2}{*}{ M3 } & PED & 15 & & & $\begin{array}{l}0.534 \\
(100.0 \%)\end{array}$ & n.a & $\begin{array}{l}0.534 \\
(100.0 \%)\end{array}$ & 0.525 & 64.170 \\
\hline & BIKE & 13 & & & $\begin{array}{l}0.455 \\
(100.0 \%)\end{array}$ & n.a & $\begin{array}{l}0.455 \\
(100.0 \%)\end{array}$ & 0.436 & 23.410 \\
\hline \multirow[t]{2}{*}{ M4 } & PED & 38 & & $\begin{array}{l}0.016 \\
(2.9 \%)\end{array}$ & $\begin{array}{l}0.397 \\
(72.2 \%)\end{array}$ & $\begin{array}{l}0.137 \\
(24.9 \%)\end{array}$ & $\begin{array}{l}0.550 \\
(100.0 \%)\end{array}$ & 0.531 & 29.370 \\
\hline & BIKE & 18 & & $\begin{array}{l}0.010 \\
(2.1 \%)\end{array}$ & $\begin{array}{l}0.344 \\
(74.0 \%)\end{array}$ & $\begin{array}{l}0.111 \\
(23.9 \%)\end{array}$ & $\begin{array}{l}0.465 \\
(100.0 \%)\end{array}$ & 0.438 & 17.330 \\
\hline \multirow[t]{2}{*}{ M5 } & PED & 41 & $\begin{array}{l}0.050 \\
(23.5 \%)\end{array}$ & $\begin{array}{l}0.062 \\
(28.7 \%)\end{array}$ & & $\begin{array}{l}0.102 \\
(47.8 \%)\end{array}$ & $\begin{array}{l}0.215 \\
(100.0 \%)\end{array}$ & 0.183 & 6.756 \\
\hline & BIKE & 11 & $\begin{array}{l}0.022 \\
(17.2 \%)\end{array}$ & $\begin{array}{l}0.009 \\
(6.8 \%)\end{array}$ & & $\begin{array}{l}0.099 \\
(76.0 \%)\end{array}$ & $\begin{array}{l}0.130 \\
(100.0 \%)\end{array}$ & 0.104 & 4.988 \\
\hline \multirow[t]{2}{*}{ M6 } & PED & 33 & $\begin{array}{l}0.019 \\
(3.4 \%)\end{array}$ & & $\begin{array}{l}0.388 \\
(70.3 \%)\end{array}$ & $\begin{array}{l}0.145 \\
(26.3 \%)\end{array}$ & $\begin{array}{l}0.552 \\
(100.0 \%)\end{array}$ & 0.536 & 33.980 \\
\hline & BIKE & 19 & $\begin{array}{l}0.008 \\
(1.7 \%)\end{array}$ & & $\begin{array}{l}0.356 \\
(76.8 \%)\end{array}$ & $\begin{array}{l}0.100 \\
(21.5 \%)\end{array}$ & $\begin{array}{l}0.463 \\
(100.0 \%)\end{array}$ & 0.435 & 16.250 \\
\hline \multirow[t]{2}{*}{ M7 } & PED & 56 & $\begin{array}{l}0.010 \\
(1.9 \%)\end{array}$ & $\begin{array}{l}0.008 \\
(1.4 \%)\end{array}$ & $\begin{array}{l}0.346 \\
(61.7 \%)\end{array}$ & $\begin{array}{l}0.196 \\
(35.0 \%)\end{array}$ & $\begin{array}{l}0.560 \\
(100.0 \%)\end{array}$ & 0.534 & 20.910 \\
\hline & BIKE & 24 & $\begin{array}{l}0.003 \\
(0.7 \%)\end{array}$ & $\begin{array}{l}0.005 \\
(1.1 \%)\end{array}$ & $\begin{array}{l}0.338 \\
(72.3 \%)\end{array}$ & $\begin{array}{l}0.121 \\
(25.9 \%)\end{array}$ & $\begin{array}{l}0.468 \\
(100.0 \%)\end{array}$ & 0.432 & 12.950 \\
\hline
\end{tabular}

$x^{*}$ Number of independent variables included in the model

Comm.** Commonalities or redundancy (n.a.: not applicable)

contribution of P-variables is four times greater for pedestrians and 3.25 greater for bicyclists compared with the pure contribution of O-variables and G-variables (M1 to M3). For bicyclists, the model considering only P-variables reaches $=R_{P}^{2} 0.455$, while models considering only G-variables and $\mathrm{O}$-variables reach a fraction of the explanatory power (barely $=R_{G}^{2} 0.108$ and $=R^{2}{ }_{O}^{0.121}$ ). Those models including P-variables (i.e., M3, M4, M6, and M7), have a greater adjusted coefficient of determination.

When comparing models combining the three groups of variables (M4 to M7), we again found coincidence between pedestrian and bicyclists in the disaggregated contribution of the groups of variables to the coefficient of determination in each model. The partial coefficient of determination of P-variables in M4, M6, and M7 is dominant. For instance, in M4, the contribution of P-variables accounts for more than 24 times the contribution percentage of $\mathrm{O}$-variables for pedestrians and more than 35 times for bicyclists. Similarly, in M6 and M7, the partial coefficient of determination of P-variables is considerably higher in comparison to the pure or combined coefficient of determination of G- and O- variables, for both modes of transportation. Table 6 presents the partial 
coefficient of determination (partial $R^{2}$ with percentage of contribution), commonalities, and the adjusted coefficient of determination $\left(\operatorname{adj}-R^{2}\right)$ for M1 to M7.

The models where various groups of variables are combined (M4 to M7), reveal both the higher contribution of P-variables and the mutual overlapping effect of G-variables and $\mathrm{O}$-variables. Commonalities provide information on the fraction of the partial contribution to the explanation of variance that cannot be allocated to a given group of variables. In addition, models considering P-variables have a higher coefficient of determination for both pedestrians and bicyclists and commonalities represent a smaller proportion of the total coefficient of determination. Conversely, models considering O-variables and G-variables simultaneously, show a substantially higher proportion of commonalities, and a lower pure effect that can be allocated to each group, implying an overshadowing effect between them. Similarly, models that include P-variables have a better fit (i.e., Lack-of-fit F-test) compared with those without them (M1, M2, and M5).

Given the high power of P-variables and leaving the big picture aside, we examined the specific P-variables that explain the perceived QoS for pedestrians and bicyclists. Similarities were again found for both. Four perceptional variables appear in both models as significant: surface condition, enjoyment, signage, and road safety. Both the significance and the relative contribution of each of the variables compared to the others, is quite similar for pedestrians and bicyclists. In both cases, the perception of the surface is the regressor with the highest contribution to QoS.

Table 7 Full models considering pedestrian and bicyclist perceptions

\begin{tabular}{|c|c|c|c|c|c|c|c|c|}
\hline & \multicolumn{4}{|l|}{ Pedestrian } & \multicolumn{4}{|l|}{ Bicyclist } \\
\hline & Coefficient & $t$ value & $p$ value & Sig & Coefficient & $t$ value & $p$ value & Sig \\
\hline Intercept & 1.655 & 7.047 & 0.000 & $* * *$ & 0.423 & 2.054 & 0.041 & $*$ \\
\hline Surface condition $^{\mathrm{a}}$ & 0.272 & 11.828 & 0.000 & $* * *$ & 0.436 & 10.270 & 0.000 & $* * *$ \\
\hline Enjoyment $^{\mathrm{a}}$ & 0.101 & 4.870 & 0.000 & $* * *$ & 0.173 & 3.935 & 0.000 & $* * *$ \\
\hline Road safety ${ }^{\mathrm{a}}$ & 0.048 & 2.541 & 0.011 & $*$ & 0.078 & 1.955 & 0.051 & . \\
\hline Signage $^{\mathrm{a}}$ & 0.072 & 3.466 & 0.001 & $* * *$ & 0.140 & 3.521 & 0.000 & $* * *$ \\
\hline Pedestrian/bicyclist presence ${ }^{\mathrm{a}}$ & 0.040 & 1.772 & 0.077 & . & & & & \\
\hline HGV flow perception & -0.050 & -3.098 & 0.002 & $* *$ & & & & \\
\hline Façades perception & 0.212 & 8.700 & 0.000 & $* * *$ & & & & \\
\hline Cleanliness & 0.040 & 1.863 & 0.063 & . & & & & \\
\hline Furniture & 0.065 & 2.757 & 0.006 & $* *$ & & & & \\
\hline Trees $^{\mathrm{a}}$ & 0.079 & 4.314 & 0.000 & $* * *$ & & & & \\
\hline Avoid infrastructure ${ }^{\mathrm{a}, \mathrm{b}}$ & & & & & 0.050 & 1.458 & 0.146 & \\
\hline R-squared & 0.525 & & & & 0.449 & & & \\
\hline Adj R-squared & 0.521 & & & & 0.442 & & & \\
\hline Full model AIC & 1299.530 an & d 16 parar & neters & & -94.536 an & 14 para & neters & \\
\hline Stepwise model AIC & 1292.929 an & d 11 parar & neters & & $-106.111 \mathrm{a}$ & id 06 par & ameters & \\
\hline
\end{tabular}

Significance codes: $* * * p<0.001 ; * * p<0.010 ; * p<0.050 ; . p<0.100$

${ }^{\text {a }}$ The question was asked for both modes; otherwise, it was only asked for pedestrians

${ }^{\mathrm{b}}$ Included in the final model due to its impact on AIC minimization; however, it does not comply with any significance level 
Regarding only the four common variables, we found that enjoyment has the second highest coefficient, which is about 0.38 times the magnitude of the surface condition's coefficient. Similarly, the signage coefficient is almost 1.5 times that of road safety. Table 7 presents the results of both models.

Table 7 shows that many more P-variables explain pedestrian QoS to a significant level, than they do for bicycles. For example, many other perceived attributes such as the beauty of facades, arborization, presence of furniture, cleanliness, and HGV flow perceptions are also relevant in explaining individuals perceived pedestrian QoS. However, we cannot draw any conclusions regarding the fact that more variables show significance in the pedestrian model. This could be the consequence of either the questionnaire being more extensive for pedestrians than for bicyclists, or that the stimuli have a greater effect on pedestrians than on bicyclists. However, the extra variables do not necessarily imply a better fit of the pedestrian model since both models have similar adjusted R-squared values.

\section{Discussion and implications}

Historically, transportation offerings have been classified into two groups: infrastructure and service provision. Transportation infrastructure is generally public, and it is provided under standards, while transportation services (e.g., transit or couriers) are customized. Services intrinsically imply the payment of a fare or fee for access. Thus, sidewalks and bike paths fall into the infrastructure transportation offering.

Not that long ago, Pine and Gilmore (1998) identified a higher economic offering called "experience." Historically, experiences have been lumped in with services, but experiences are a distinct economic offering, as different from services as services are from goods (Table 8). Experiences, unlike services, are related to individuals' sensory events, revealed over the duration, which are memorable. Experience is not a vague construct (Pine and Gilmore 1998). Unlike services, the delivery of experiences in transportation, may or may not command a fee (first-class flight or a sidewalk).

Evidence from this research shows that pedestrians and bicyclists are not only consuming the infrastructure capacity to move through it as a "user," but that other sensory-related factors are somehow more relevant (e.g., pleasantness, safety, enjoyment). Let us recall that the initial pedestrian and bicyclist SPI, namely the LOS, was developed in the 1980s, much earlier than the theoretical background provided by Pine and Gilmore (1998). Based on the similarities in the flow characteristics with cars, non-motorized infrastructures were associated with roads and highways. Unintendedly, early LOS methods for non-motorized modes "commoditized" sidewalks and bicycle paths and pigeonholed them into the "goods" offering (Table 8). One of the primary purposes of this research is to reclaim the "customization" of a more accurate and up-to-date transport delivery of active modes infrastructure.

Without excluding sidewalks and bicycle infrastructure from rendering the "goods" offering, evidence found in this research suggests that non-motorized infrastructures fall also into the transportation experience offering (Table 8). Sidewalks and bicycle paths must provide the safe and efficient movement of people, with good physical characteristics and considering the traditional relationship between demand and capacity to avoid congestion. Thus, G- and O-variables are indeed needed to evaluate the performance, just as audits are needed to guarantee the standard requirements, even when considering behavioral studies (Ortiz-Ramirez et al. 2021). 
Table 8 Progression of economic value applied for transportation offerings. Modified from Pine and Gilmore (1998)

\begin{tabular}{llll} 
& \multicolumn{2}{c}{ Customization } & \\
& Goods & Services & Experiences \\
\hline Economic offering & Function & Services & Experience \\
Evaluation (SPI) & Performance & Quality of service & Satisfaction \\
Intrinsic function & Supply & Deliver & Stage \\
Factors of demand & Capacity & Quality & Uniqueness/ \\
Factors of reward & Features & Benefits & Aesthetics \\
Nature of offering & Tangible & Sensations \\
Key Attribute & Standardized & Customized & Memorable \\
Method of supply & Inventoried after & Delivered on demand & Revealed over a \\
production & duration \\
Seller & Manufacturer & Provider & Stager \\
Consumer & User & Customer & Guest
\end{tabular}

Example

Highway

\section{Commoditization}

Sidewalk

A popular sentence by Drucker (2007) that states that service is something that the customer receives not something that the supplier provides, brings into the discussion the supply-oriented evaluation of non-motorized quality of service, under the evidence provided by this research. In principle, O- and G-variables (supply-oriented) can assure infrastructure function and performance, but not necessarily meeting users' (guests) needs to maximize their individually perceived QoS. The great contribution of intangible and perceptual inputs to explain QoS, such as safety, pleasure, or security, reclaims the consideration of user inputs into the framework for non-motorized SPIs.

The importance of individuals' input into the planning, design, and operations of nonmotorized infrastructures is associated with the undeniable sensorial experience of walking and bicycling. For planners, designers, and engineers, the evaluation of a given nonmotorized infrastructure, in practical terms, is undoubtedly easier by means of counting or measuring something tangible (G- and O-variables). The lack of familiarity and apparent lack of practical convenience of P-variables leads the discussion to consider whether the most significant individual perceptions (e.g., pleasure) can be related with a specific physical condition in the right-of-way.

Recent research by Vallejo-Borda et al. (2020b) has found a practical application of perceptions to assess sidewalks. They use perceptions as mediators to estimate a perceived QoS model based on objective variables through multiple causes and multiple indicators (MIMIC) modeling. Furthermore, Barrero and Rodriguez-Valencia (2021) have shown that understanding how users perceive the built environment can allow enhancing infrastructure 
evaluation and design processes. Since they rely on assessing the attributes that are most valued for user satisfaction, these enhancements can help to provide approachable places that contribute to the promotion of non-motorized transportation. Habib et al. (2014) also found that there is a major component of comfort in bicyclists' decision of owning and using a bicycle to commute. However, despite these findings, comfort, pleasure, and other psychological factors have not been incorporated into the infrastructure's design guidelines or design process. The incorporation of these factors may complement the infrastructure quality assessment and provide decision-makers with strategies that positively impact the choice of active modes towards non-motorized transportation promotion.

Non-motorized transportation is key to attaining sustainable development. In line with this, increases in non-motorized infrastructure are particularly relevant for urban cycling. Despite the lack of consensus on the differential effect of bike infrastructure provision on demand (Buehler and Dill 2016), in Bogota, the proximity of households to a bicycle linear facility has shown a small but significant positive difference in bicycling rates (Rodriguez-Valencia et al. 2019). However, this increase is associated with the idea of induced demand that appears when infrastructure supply increases or with transit quality of service decreases (Rodriguez-Valencia et al. 2021), but not due to the intrinsic attractivity of the activity. Hence, complementing infrastructure evaluation with subjective assessments can provide insight into how the built environment is perceived and how it can render a bicycling experience that attracts users. Also, it could provide information on the attributes that motivate users to regularly commute using their bicycle from a volitional perspective, rather than influenced by external factors.

Further research is required to better understand the relationships between behaviors and non-motorized SPIs, as suggested by Ewing and Handy (2009). The environmental psychology model proposed by Mehrabian and Russell (1974) can be useful in assessing this kind of relationship. The model relates environmental stimuli with avoid or approach behaviors and suggests that stimuli elicit affective responses related to comfort and satisfaction, which are two commonly used dependent variables in SPIs. As part of this theory, it is proposed that increased pleasure (measured through comfort, satisfaction, happiness, among others) is associated with positive emotional responses and subsequently with approach behaviors, as shown by Ortiz-Ramirez et al. (2021). However, as we have commented, these kinds of variables and factors are not commonly used as SPI explanators, thus failing to capture the information related to subjectivity, its impact on service and performance estimation, and the effects of the SPIs on behaviors.

Despite the differences in terms of operation between pedestrians and bicyclists, and the fact that data came from two separate and independent surveys, there are great similarities in the results for both modes of transportation with respect to the relative power of P-variables and in their specific regressors. This finding provides evidence supporting that non-motorized modes, which are in direct contact with their contexts while traveling, assess the built environment attributes in a similar way. An implication of this is that infrastructure interventions on surface conditions, signaling, enjoyment, and road safety would affect both pedestrians and bicyclists, thus, increasing the impact and efficiency of such interventions.

As a closing reflection, an academic and professional dialogue, beyond the Global North is required to advance towards a comprehensive, diverse, inclusive SPI framework for non-motorized modes of transportation. A few more years are required to evolve the idea that sidewalks, bicycle paths, and other transportation infrastructures might fall into the offering of experience transportation (Table 8). Another topic that requires discussion is the variable to be evaluated in a given SPI. Why QoS or stress? Beyond pedestrian and 
bicyclists SPI history, and the great contribution that previous developments have rendered to society, more transparency and clarity is needed when reporting the research dependent variable.

\section{Conclusions}

This study proposes a comprehensive framework for pedestrian and bicycle infrastructure evaluation including the user-oriented input or perceptions. The framework was constructed based on evidence that P-variables provide a great explanatory power for pedestrians' and bicyclists' individually perceived quality of service at roadway segments. A review and analysis of existing state-of-the-art pedestrian and bicyclists SPIs, together with theory on environmental psychology and transportation behavior, enriches and contributes to a broader and more general framework based on which to evaluate non-motorized infrastructure.

The substantial contribution of users' perceptions to explain non-motorized infrastructure QoS involves the characteristics of the traditional infrastructure assessment into discussion. First, focusing only on supply-oriented measures of the infrastructure, neglects the influence of people's perceptions on the built environment, and second, neglecting such subjectivities makes it difficult to understand the relationship between infrastructure perception and valuation (i.e., attitudes towards the infrastructure or modes) and behaviors such as approaching active modes of transportation.

From this perspective, we suggest that, beyond being considered a good, streets constitute a stage where people must be treated as guests, not as users. We claim that sidewalks and bike paths must be improved in terms of their transportation offering towards "customization" which implies an understanding of active transportation as an experience itself rather than a mere service. Accordingly, SPIs have the potential to be enriched with new measures related to the experience of walking and bicycling and by considering trip purposes. With more pleasant experiences, we can expect approaching behavior towards these modes, as has been broadly proposed in the literature. Besides, the different trip purposes may change the definition of a pleasant experience (e.g., arborization, route directness), highlighting the importance of considering such specifications.

From our study, it is possible to propose that the estimation of SPIs can be enhanced by including user perceptions. Hence, future research should focus on re-developing broadly known indices including P-variables to prove our framework. To do so, interception surveys can be designed and calibrated using the P-variables that we found to be common for both users since they proved to be highly relevant in terms of perceived QoS assessment for both modes. As was suggested by the R-squared values obtained by applying our models, there are no significant multicollinearity problems; however, a more in-depth future examination, including thorough correlation analyses between factors is recommended. Furthermore, the proposed relationship between the SPIs and behaviors can be proved with evidence in future research. To understand such relationship, studies can focus on measuring how SPIs impact both behaviors and behavioral intentions. Measuring this mechanism can provide information on how the service or performance provided by an infrastructure can exert an influence on active traveling and route choice.

In terms of the limitations of our study, we wish to mention that our research focuses only on segment analysis, meaning that crossings are not considered in assessing QoS, and that including them could enhance our findings. We also decided not to include users' 
affective experience, which could provide further information on how QoS perception varies due to the individuals' heterogeneity. However, this kind of analysis justifies a different study to reveal how affective experience can impact infrastructure valuation. Further studies should also examine different SPIs in order to discover the role of perceptions in explaining each of them. This would provide information on the differences between the SPIs; for example, between QoS and LOS. Finally, studies replicating our methods on different cities could be beneficial to the generalizability of the proposed framework.

Acknowledgements The authors are grateful for the support received by MINCIENCIAS under forgivable loan 6172, as well as the School of Engineering and the Vice-presidency of Research and Creation at Universidad de los Andes for financing the doctoral research of two of the authors of this paper. Other internal research resources from Universidad de los Andes and the Sostenibilidad Urbana y Regional (SUR) Research Group were also necessary to make this research possible.

Author contributions Conceptualization: AR-V; Methodology: JAV-B, GAB, HAO-R; Formal analysis and investigation: JAV-B, GAB, HAO-R; Writing — original draft preparation: AR-V, JAV-B, GAB, HAO-R; Writing — review and editing: AR-V, JAV-B, GAB, HAO-R; Funding acquisition: AR-V; Resources: AR-V; Supervision: AR-V.

\section{Funding None.}

\section{Declarations}

Conflict of interest Authors declare that they do not have any conflict of interest.

Open Access This article is licensed under a Creative Commons Attribution 4.0 International License, which permits use, sharing, adaptation, distribution and reproduction in any medium or format, as long as you give appropriate credit to the original author(s) and the source, provide a link to the Creative Commons licence, and indicate if changes were made. The images or other third party material in this article are included in the article's Creative Commons licence, unless indicated otherwise in a credit line to the material. If material is not included in the article's Creative Commons licence and your intended use is not permitted by statutory regulation or exceeds the permitted use, you will need to obtain permission directly from the copyright holder. To view a copy of this licence, visit http://creativecommons.org/licenses/by/4.0/.

\section{References}

Ali, J., Perumal, S., Shaari, H.: Application of the stimulus-organism-response model in the airline industry: examining mediating role of airline image in repurchase intention. Int. J. Supply Chain Manag. 9(2), 981-989 (2020)

Appolloni, L., Corazza, M.V., D’Alessandro, D.: The pleasure of walking: an innovative methodology to assess appropriate walkable performance in urban areas to support transport planning. Sustainability (Switzerland) (2019). https://doi.org/10.3390/su11123467

Asadi-Shekari, Z., Moeinaddini, M., Zaly Shah, M.: Non-motorised level of service: addressing challenges in pedestrian and bicycle level of service. Transp. Rev. 33(2), 166-194 (2013). https://doi.org/10.1080/ 01441647.2013 .775613

Barrero, G.A., Rodriguez-Valencia, A.: Asking the user: a perceptional approach for bicycle infrastructure design. Int. J. Sustain. Transp. (2021). https://doi.org/10.1080/15568318.2020.1871127

Bellizzi, M.G., Eboli, L., Forciniti, C.: Segregation vs interaction in the walkways: an analysis of pedestrians' perceptions. Res. Transp. Bus. Manag. (2019). https://doi.org/10.1016/j.rtbm.2019.100410

Bivina, G.R., Parida, M.: Modelling perceived pedestrian level of service of sidewalks: a structural equation approach. Transport 34(3), 339-350 (2019). https://doi.org/10.3846/transport.2019.9819

Blaison, C., Hess, U.: Affective judgment in spatial context: how places derive affective meaning from the surroundings. J. Environ. Psychol. 47, 53-65 (2016). https://doi.org/10.1016/j.jenvp.2016.05.005 
Bornioli, A., Parkhurst, G., Morgan, P.L.: Affective experiences of built environments and the promotion of urban walking. Transp. Res. Part A Policy Pract. (2019). https://doi.org/10.1016/j.tra.2018.12.006

Buehler, R., Dill, J.: Bikeway networks: a review of effects on cycling. Transp. Rev. 36(1), 9-27 (2016). https://doi.org/10.1080/01441647.2015.1069908

Dandan, T., Wei, W., Jian, L., Yang, B.: Research on methods of assessing pedestrian level of service for sidewalk. J. Transp. Syst. Eng. Inf. Technol. 7(5), 74-79 (2007). https://doi.org/10.1016/S15706672(07)60041-5

De Vos, J., Mokhtarian, P.L., Schwanen, T., Van Acker, V., Witlox, F.: Travel mode choice and travel satisfaction: bridging the gap between decision utility and experienced utility. Transportation 43(5), 771796 (2016). https://doi.org/10.1007/s11116-015-9619-9

Drucker, P.: Innovation and Enterpreneurship: Practice and Principles, 3rd edn. Harper \& Row, New York (2007)

Duncan, D.T., Aldstadt, J., Whalen, J., Melly, S.J., Gortmaker, S.L.: Validation of Walk Score® for estimating neighborhood walkability: an analysis of four US metropolitan areas. Int. J. Environ. Res. Public Health 8(11), 4160-4179 (2011). https://doi.org/10.3390/ijerph8114160

Evans, G.W., Stecker, R.: Motivational consequences of environmental stress. J. Environ. Psychol. 24(2), 143-165 (2004). https://doi.org/10.1016/S0272-4944(03)00076-8

Ewing, R., Handy, S.: Measuring the unmeasurable: urban design qualities related to walkability. J. Urban Des. 14(1), 65-84 (2009). https://doi.org/10.1080/13574800802451155

Ewing, R., Handy, S., Brownson, R.C., Clemente, O., Winston, E.: Identifying and measuring urban design qualities related to walkability. J. Phys. Act. Health 3(1), 223-240 (2006). https://doi.org/10.13072/ midss. 126

Fernández-Heredia, Á., Jara-Díaz, S., Monzón, A., Jara-d, S.: Modelling bicycle use intention: the role of perceptions. Transportation 43(1), 1-23 (2016). https://doi.org/10.1007/s11116-014-9559-9

Ferro Navas, S.: Percepción y nivel de servicio de infraestructura de bicicletas. Universidad de los Andes, Bogotá (2017)

Foster, N., Monsere, C.M., Dill, J., Clifton, K.: Level-of-service model for protected bike lanes. Transp. Res. Rec. 2520, 90-99 (2016). https://doi.org/10.3141/2520-11

Friman, M.: Affective dimensions of the waiting experience. Transp. Res. Part F Traffic Psychol. Behav. 13(3), 197-205 (2010). https://doi.org/10.1016/j.trf.2010.04.006

Furth, P.G., Mekuria, M.C., Nixon, H.: Network connectivity for low-stress bicycling. Transp. Res. Rec. 2587(1), 41-49 (2016). https://doi.org/10.3141/2587-06

Gallin, N.: Quantifying pedestrian friendliness-guidelines for assessing pedestrian level of service. Road Transp. Res. 10(1), 47-55 (2001)

Garrard, J., Rose, G., Lo, S.K.: Promoting transportation cycling for women: the role of bicycle infrastructure. Prev. Med. 46(1), 55-59 (2008). https://doi.org/10.1016/j.ypmed.2007.07.010

Gatersleben, B., Uzzell, D.: Affective appraisals of the daily commute: comparing perceptions of drivers, cyclists, walkers, and users of public transport. Environ. Behav. 39(3), 416-431 (2007). https://doi.org/ 10.1177/0013916506294032

Golob, T.F.: Structural equation modeling for travel behavior research. Transp. Res. Part B 37, 1-25 (2003)

Griswold, J.B., Yu, M., Filingeri, V., Grembek, O., Walker, J.L.: A behavioral modeling approach to bicycle level of service. Transp. Res. Part A Policy Pract. 116(2017), 166(May) - 177 (2018). https://doi.org/ 10.1016/j.tra.2018.06.006

Gujarati, D., Porter, D.: Econometria. McGraw Hill, Mexico (2010)

Guo, Z., Loo, B.P.Y.: Pedestrian environment and route choice: evidence from New York City and Hong Kong. J. Transp. Geogr. 28, 124-136 (2013). https://doi.org/10.1016/j.jtrangeo.2012.11.013

Habib, K.N., Mann, J., Mahmoud, M., Weiss, A.: Synopsis of bicycle demand in the City of Toronto: investigating the effects of perception, consciousness and comfortability on the purpose of biking and bike ownership. Transp. Res. Part A Policy Pract. 70, 67-80 (2014). https://doi.org/10.1016/j.tra.2014.09. 012

Harkey, D.L.: The Bicycle Compatibility Index: A Level of Service Concept, p. 4. Turner-Fairbank Highway Research Center, McLean (1998)

Health, S.U., Team, P.: SFDPH Program on Health, Equity, and Sustainability Urban Health and Place Team Bicycle Environmental Quality Index-June (2010)

Huertas, J.A., Palacio, A., Botero, M., Carvajal, G.A., van Laake, T., Higuera-Mendieta, D., Cabrales, S.A., Guzman, L.A., Sarmiento, O.L., Medaglia, A.L.: Level of traffic stress-based classification: a clustering approach for Bogotá, Colombia. Transp. Res. Part D Transp. Environ. (2020). https://doi.org/10. 1016/j.trd.2020.102420 
Jahan, M.I., Mazumdar, A.A., Hadiuzzaman, M., Mashrur, S.M., Murshed, M.N.: Analyzing service quality of pedestrian sidewalks under mixed traffic condition considering latent variables. J. Urban Plan. Dev. 146(2), 1-12 (2020). https://doi.org/10.1061/(ASCE)UP.1943-5444.0000563

Jang, S.C., Namkung, Y.: Perceived quality, emotions, and behavioral intentions: application of an extended Mehrabian-Russell model to restaurants. J. Bus. Res. 62(4), 451-460 (2009). https://doi.org/10.1016/j. jbusres.2008.01.038

Jensen, S.U., Underlien, S., Jensen, S.U.: Pedestrian and bicyclist level of service on roadway segments. Transp. Res. Rec. 2031(2031), 43-51 (2007). https://doi.org/10.3141/2031-06

Kadali, B.R., Vedagiri, P.: Evaluation of pedestrian crosswalk level of service (LOS) in perspective of type of land-use. Transp. Res. Part A Policy Pract. 73, 113-124 (2015). https://doi.org/10.1016/j.tra.2015. 01.009

Kitamura, R., Mokhtarian, P.L., Laidet, L.: A micro-analysis of land use and travel in five neighborhoods in the San Francisco Bay Area. Transportation 24, 125-158 (1997). https://doi.org/10.1023/A:10179 59825565

Koohsari, M.J., Owen, N., Cerin, E., Giles-Corti, B., Sugiyama, T.: Walkability and walking for transport: characterizing the built environment using space syntax. Int. J. Behav. Nutr. Phys. Act. 13(1), 1-9 (2016). https://doi.org/10.1186/s12966-016-0448-9

Landis, B.W., Vattikuti, V.R., Brannick, M.T.: Real-time human perceptions: toward a bicycle level of service. Transp. Res. Rec. 1578(970428), 119-126 (1997). https://doi.org/10.3141/1578-15

Landis, B.W., Vattikuti, V.R., Ottenberg, R.M., McLeod, D.S., Guttenplan, M.: Modeling the roadside walking environment: pedestrian level of service. Transp. Res. Rec. 1773, 82-88 (2001a). https:// doi.org/10.3141/1773-10

Landis, B.W., Vattikuti, V.R., Ottenberg, R.M., McLeod, D.S., Guttenplan, M.: Modeling the roadside walking environment: pedestrian level of service. Transp. Res. Rec. 1773(1773), 82-88 (2001b). https://doi.org/10.3141/1773-10

Landis, B.W., Vattikuti, V.R., Ottenberg, R.M., Petritsch, T.A., Guttenplan, M., Crider, L.B.: Intersection level of service for the bicycle through movement. Transp. Res. Rec. 1828(1828), 101-106 (2003). https://doi.org/10.3141/1828-12

Larrañaga, A.M., Rizzi, L.I., Arellana, J., Strambi, O., Bettella Cybis, H.B.: The influence of built environment and travel attitudes on walking: a case study of Porto Alegre, Brazil. Int. J. Sustain. Transp. 10(4), 332-342 (2016). https://doi.org/10.1080/15568318.2014.933986

Lee, S., Talen, E.: Measuring walkability: a note on auditing methods. J. Urban Des. 19(3), 368-388 (2014). https://doi.org/10.1080/13574809.2014.890040

Ma, L., Cao, J.: How perceptions mediate the effects of the built environment on travel behavior? Transportation 46(1), 175-197 (2019). https://doi.org/10.1007/s11116-017-9800-4

Maizlish, N., Linesch, N.J., Woodcock, J.: Health and greenhouse gas mitigation benefits of ambitious expansion of cycling, walking, and transit in California. J. Transp. Health 6(April), 490-500 (2017). https://doi.org/10.1016/j.jth.2017.04.011

Marquet, O., Miralles-Guasch, C.: The walkable city and the importance of the proximity environments for Barcelona's everyday mobility. Cities 42(PB), 258-266 (2015). https://doi.org/10.1016/j.cities. 2014.10.012

Mehrabian, A., Russell, J.A.: An Approach to Environmental Psychology. The Mit Press, Cambridge (1974)

Mekuria, M.C., Furth, P.G., Nixon, H.: Low-stress bicycling and network connectivity (2012). http:// transweb.sjsu.edu

Nag, D., Goswami, A.K., Gupta, A., Sen, J.: Assessing urban sidewalk networks based on three constructs: a synthesis of pedestrian level of service literature. Transp. Rev. (2019). https://doi.org/10. 1080/01441647.2019.1703841

Ortiz-Ramirez, H.A., Vallejo-Borda, J.A., Rodriguez-Valencia, A.: Staying on or getting off the sidewalk? Testing the Mehrabian-Russell model on pedestrian behavior. Transp. Res. Part F Traffic Psychol. Behav. 78, 480-494 (2021). https://doi.org/10.1016/j.trf.2021.03.007

Ortúzar, J.D.D., Willumsen, L.G.: Modelling Transport, 3rd edn. Wiley, Chichester (2011). https://doi. org/10.1002/9781119993308

Paül i Agustí, D., Rutllant, J., Lasala Fortea, J.: Differences in the perception of urban space via mental maps and Heart Rate Variation (HRV). Appl. Geogr. (2019). https://doi.org/10.1016/j.apgeog.2019. 102084

Peiravian, F., Derrible, S., Ijaz, F.: Development and application of the Pedestrian Environment Index (PEI). J. Transp. Geogr. 39, 73-84 (2014). https://doi.org/10.1016/j.jtrangeo.2014.06.020 
Petritsch, T.A., Landis, B.W., McLeod, P.S., Huang, H.F., Challa, S., Guttenplan, M.: Level-of-service model for pedestrians at signalized intersections. Transp. Res. Rec. 1939, 55-62 (2005). https://doi. org/10.1177/0361198105193900107

Pikora, T., Giles-Corti, B., Bull, F., Jamrozik, K., Donovan, R.: Developing a framework for assessment of the environmental determinants of walking and cycling. Soc. Sci. Med. 56(8), 1693-1703 (2003). https://doi.org/10.1016/S0277-9536(02)00163-6

Pine, J., Gilmore, J.H.: Welcome to the experience economy. Hadvard Bus. Rev. 76(4), 97-105 (1998)

Pucher, J., Buehler, R.: Cycling towards a more sustainable transport future. Transp. Rev. 37(6), 689694 (2017). https://doi.org/10.1080/01441647.2017.1340234

Rodriguez-Valencia, A., Rosas-Satizábal, D., Gordo, D., Ochoa, A.: Impact of household proximity to the cycling network on bicycle ridership: the case of Bogotá. J. Transp. Geogr. 79, 102480 (2019). https://doi.org/10.1016/j.jtrangeo.2019.102480

Rodriguez-Valencia, A., Barrero, G.A., Ortiz-Ramirez, H.A., Vallejo-Borda, J.A.: Power of user perception on pedestrian quality of service. Transp. Res. Rec. 2674(5), 250-258 (2020). https://doi.org/ $10.1177 / 0361198120914611$

Rodriguez-Valencia, A., Rosas-Satizabal, D., Unda, R., Handy, S.L.: The decision to start commuting by bike in Bogotá, Colombia: motivations and influences. Travel Behav. Soc. 24(March), 57-67 (2021). https://doi.org/10.1016/j.tbs.2021.02.003

Roess, R., Vandehey, M., Kittelson, W.: Level of service. Transp. Res. Rec. 2173(2173), $20-27$ (2010). https://doi.org/10.3141/2173-03

Rossetti, T., Hurtubia, R.: An assessment of the ecological validity of immersive videos in stated preference surveys. J. Choice Model. (2020). https://doi.org/10.1016/j.jocm.2019.100198

Saelens, B., Sallis, J.F., Frank, L.D.: Environmental correlates of walking and cycling: findings from the transportation, urban design, and planning literatures. Ann. Behav. Med. 25(2), 80-91 (2003). https://doi.org/10.1207/S15324796ABM2502_03

Samarasekara, G.N., Fukahori, K., Kubota, Y.: Environmental correlates that provide walkability cues for tourists: an analysis based on walking decision narrations. Environ. Behav. 43(4), 501-524 (2011). https://doi.org/10.1177/0013916510379350

Samuel, O., Walker, G., Salmon, P., Filtness, A., Stevens, N., Mulvihill, C., Payne, S., Stanton, N.: Riding the emotional roller-coaster: using the circumplex model of affect to model motorcycle riders' emotional state-changes at intersections. Transport. Res. Part F Traffic Psychol. Behav. 66, 139-150 (2019). https://doi.org/10.1016/j.trf.2019.08.018

Scherrer, B., Legendre, P., Beltangady, M.: Biostatistique, 2nd edn. G. Morin, Quebec (2009)

Schneider, R.J.: Theory of routine mode choice decisions: an operational framework to increase sustainable transportation. Transp. Policy 25, 128-137 (2013). https://doi.org/10.1016/j.tranpol.2012.10. 007

Sehatzadeh, B., Noland, R.B., Weiner, M.D.: Walking frequency, cars, dogs, and the built environment. Transp. Res Part A Policy Pract. 45(8), 741-754 (2011). https://doi.org/10.1016/j.tra.2011.06.001

Shatu, F., Yigitcanlar, T.: Development and validity of a virtual street walkability audit tool for pedestrian route choice analysis-SWATCH. J. Transp. Geogr. 70(June), 148-160 (2018). https://doi.org/ 10.1016/j.jtrangeo.2018.06.004

Stockton, J.C., Duke-Williams, O., Stamatakis, E., Mindell, J.S., Brunner, E.J., Shelton, N.J.: Development of a novel walkability index for London, United Kingdom: cross-sectional application to the Whitehall II Study. BMC Public Health 16(1), 1-12 (2016). https://doi.org/10.1186/s12889-016-3012-2

Transportation Research Board: HCM 2010: Highway Capacity Manual (2010)

Tsiompras, A.B., Photis, Y.N.: What matters when it comes to "walk and the city"? Defining a weighted GIS-based walkability index. Transp. Res. Procedia 24, 523-530 (2017). https://doi.org/10.1016/j. trpro.2017.06.001

Tyler, T.R., Huo, Y.J., Lind, E.A.: The two psychologies of conflict resolution: differing antecedents of pre-experience choices and post-experience evaluations. Group Process. Intergroup Relat. 2(2), 99-118 (1999). https://doi.org/10.1177/07399863870092005

Vallejo-Borda, J., Rosas-Satizabal, D., Rodriguez-Valencia, A.: Cyclists' perceived infrastructure service quality and enjoyment: a SEM approach. 98th Transportation Research Board Annual Meeting (2019)

Vallejo-Borda, J.A., Ortiz-Ramirez, H.A., Rodriguez-Valencia, A., Hurtubia, R., Ortúzar, J.D.D.: Forecasting the quality of service of Bogota's sidewalks from pedestrian perceptions: an ordered probit MIMIC approach. Transp. Res. Rec. 2674(1), 205-216 (2020). https://doi.org/10.1177/0361198119896782

Vallejo-Borda, J.A., Cantillo, V., Rodriguez-Valencia, A.: A perception-based cognitive map of the pedestrian perceived quality of service on urban sidewalks. Transp. Res. Part F Psychol. Behav. 73, 107-118 (2020a). https://doi.org/10.1016/j.trf.2020.06.013 
Vallejo-Borda, J.A., Rosas-Satizábal, D., Rodriguez-Valencia, A.: Do attitudes and perceptions help to explain cycling infrastructure quality of service? Transp. Res. Part D Transp. Environ. 87, 102539 (2020c). https://doi.org/10.1016/j.trd.2020.102539

van Acker, V., van Wee, B., Witlox, F.: When transport geography meets social psychology: toward a conceptual model of travel behaviour. Transp. Rev. 30(2), 219-240 (2010). https://doi.org/10.1080/ 01441640902943453

van Wee, B., De Vos, J., Maat, K.: Impacts of the built environment and travel behaviour on attitudes: theories underpinning the reverse causality hypothesis. J. Transp. Geogr. 80(September), 102540 (2019). https://doi.org/10.1016/j.jtrangeo.2019.102540

Wang, H., Palm, M., Chen, C., Vogt, R., Wang, Y.: Does bicycle network level of traffic stress (LTS) explain bicycle travel behavior? Mixed results from an Oregon case study. J. Transp. Geogr. 57, 8-18 (2016). https://doi.org/10.1016/j.jtrangeo.2016.08.016

Washington, S.P., Karlaftis, M.G., Mannering, F.L.: Statistical and Econometric Methods for Transportation Data Analysis, 2nd edn. Taylor \& Francis Group, CRC Press, Boca Raton (2011)

World Health Organization: A Physically Active Life Through Everyday Transport. Regional Office for Europe, København (2002)

Wu, H., Leung, S.O.: Can likert scales be treated as interval scales?-A simulation study. J. Soc. Serv. Res. 43(4), 527-532 (2017). https://doi.org/10.1080/01488376.2017.1329775

Xia, T., Zhang, Y., Braunack-Mayer, A., Crabb, S.: Public attitudes toward encouraging sustainable transportation: an Australian case study. Int. J. Sustain. Transp. 11(8), 593-601 (2017). https://doi.org/10. 1080/15568318.2017.1287316

Yani-de-Soriano, M.M., Foxall, G.R.: The emotional power of place: the fall and rise of dominance in retail research. J. Retail Consum. Serv. 13(6), 403-416 (2006). https://doi.org/10.1016/j.jretconser.2006.02. 007

Zhang, M., Ihme, K., Drewitz, U.: Discriminating drivers' emotions through the dimension of power: evidence from facial infrared thermography and peripheral physiological measurements. Transport. Res. Part F Traffic Psychol. Behav. 63, 135-143 (2019). https://doi.org/10.1016/j.trf.2019.04.003

Publisher's Note Springer Nature remains neutral with regard to jurisdictional claims in published maps and institutional affiliations.

Alvaro Rodriguez-Valencia is an assistant professor at the School of Engineering at Universidad de los Andes Bogotá, working on travel behavior. He has been consultant for the United Nations and author of two books related with transportation planning in Bogotá. He is member of two Standing Committees at the Transportation Research Board, of the National Academies of Sciences, Engineering, and Medicine of the United States of America.

Jose Agustin Vallejo-Borda is a Postdoctoral Researcher at BRT+ Centre of Excellence in Pontificia Universidad Católica de Chile. His primary interest is applying advanced statistical and econometrics models (e.g., hybrid discrete choice models) to understand the behaviour of one variable using explanatory variables. He has specific experience in user satisfaction modelling, measurement instruments design, and development of studies based on preferences with ordinary least squares (OLS), ordered, discrete, and discrete-continuous models.

German A. Barrero is an architect and civil engineer, currently working in the Bogotá's Department of Transportation. Magister on transportation engineering focusing on sustainable mobility and the recovery of the public space though tactical urbanism and infrastructure projects.

Hernan Alberto Ortiz-Ramirez is an engineering $\mathrm{PhD}$ student focused on travel behavior, transportation psychology, and motivation. Industrial designer and magister on architecture. Doctoral research assistant at the Sostenibilidad Urbana y Regional (SUR) research center. 


\section{Authors and Affiliations}

\section{Alvaro Rodriguez-Valencia ${ }^{1}$ (D) . Jose Agustin Vallejo-Borda ${ }^{2,3}$ (D) . German A. Barrero ${ }^{4}$ D . Hernan Alberto Ortiz-Ramirez ${ }^{4}$}

Jose Agustin Vallejo-Borda

ja.vallejo907@uniandes.edu.co

German A. Barrero

ga.barrero192@uniandes.edu.co

Hernan Alberto Ortiz-Ramirez

ha.ortiz10@uniandes.edu.co

1 Department of Civil and Environmental Engineering and Director of Sostenibilidad Urbana y Regional (SUR) Research Group, Universidad de Los Andes, Carrera 1E N ${ }^{\circ}$ 19A-40, 111711 Bogotá, Colombia

2 BRT + Centre of Excellence, Department of Transport Engineering and Logistics, Pontificia Universidad Católica de Chile, Avda. Vicuña Mackenna 4860, Macul, Santiago, Chile

3 AVR Research Group, Department of Civil Engineering, Universidad de Investigación y Desarrollo, Bucaramanga, Colombia

4 Sostenibilidad Urbana y Regional (SUR) Research Group, Department of Civil and Environmental Engineering, Universidad de Los Andes, Carrera 1E N 19A-40, 111711 Bogotá, Colombia 